\title{
The Mechanism of Diazo-coupling to Indoles and the Effect of Steric Hindrance on the Rate-limiting Step
}

\author{
By Brian C. Challis * and Henry S. Rzepa, Department of Chemistry, Imperial College, London SW7 2AZ
}

The first syntheses of 4-methyl-2-t-butyl-and 2-methyl-4,6-di-t-butyl-indole are described. Rates of diazocoupling at the 3-position of both these compounds together with those for 2-methyl-and 2-t-butyl-indole are reported for various para-substituted arenediazonium ions in mixed aqueous and some aprotic solvents at $25^{\circ}$. The kinetic behaviour of 2-methylindole is examined in detail and it is shown that 3-coupling may proceed through either the neutral compound or the 2-methylindolyl anion depending on the $\mathrm{pH}$, with the anion being $\mathrm{ca}$. $10^{8}$-fold more reactive. For neutral 2-methylindole coupling, rates increase with increasing reactivity of the diazonium ion giving $\rho 3.3$ for the Hammett $\left(\rho \sigma^{+}\right)$plot, and for coupling with $p$-toluenediazonium ion $\Delta H^{\ddagger}=38 \mathrm{~kJ}$ mol-1 and $\Delta S^{*}=138 \mathrm{~J} \mathrm{~K}^{-1} \mathrm{~mol}^{-1}$. Kinetic isotope effects for coupling to $\left[3-{ }^{2} \mathrm{H}_{1}\right]$ - and $\left[3-{ }^{3} \mathrm{H}_{1}\right]-2$-methylindole and 3 deuteriated 2-t-butyl-and 4-methyl-2-t-butyl-indole are not apparent in aqueous dioxan. Coupling to 2 -methyl4,6-di-t-butylindole is also shown to proceed via both the neutral substrate and its conjugate base, but these reactions show significant primary hydrogen isotope effects $\left(k^{\mathrm{H}} / k^{\mathrm{D}} c a .7\right)$. The results are interpreted in terms of a classical $A-S_{\mathrm{E}} 2$ mechanism for both neutral indoles and indolyl anions in which direct electrophilic attack by the arene diazonium ion at the 3-position is normally rate limiting. The change in the rate limiting step observed for the $A-S_{\mathrm{F}} 2$ mechanism with 2-methyl-4,6-di-t-butylindole is attributed to steric hindrance acting only on proton expulsion in a very reactant-like transition state and not on attack of the electrophilic diazonium ion. There is no evidence for coupling to indole nitrogen and triazene intermediates are therefore not significant in any of these reactions.

ARENEDiazonium ions are mildly electrophilic reagents capable of substituting activated aromatic compounds. The mechanism of these reactions is well established by the work of Zollinger, ${ }^{1}$ who demonstrated an $A-S_{\mathrm{E}} 2$ mechanism (Scheme 1) for coupling to naphthols. With

1 H. Zollinger, Helv. Chim. Acta (a) 1955, 38, 1597, 1617, 1623 . (b) $1958,41,2274$. For a recent review see H. Zollinger, Angew. Chem. Internat. Edn., 1972, 11, 874. certain hindered hydroxy naphthalenesulphonic acids, the coupling reactions exhibited large primary deuterium isotope effects, which implied that proton transfer from the Wheland intermediate (step $k_{\mathrm{b}}$ ) could be almost entirely rate limiting. ${ }^{1 a}$

We have reported isotopic rate ratios for the hydrogen

2 B. C. Challis and E. M. Millar, J.C.S. Perkin II, $1972(a)$ $1116 ;$ (b) 1618,1625 . 
exchange of indoles ${ }^{2}$ and shown that their magnitude is largely independent of substrate reactivity and, inter alia, the symmetry of the transition state for proton transfer. ${ }^{2 b}$ Derivation of primary deuterium

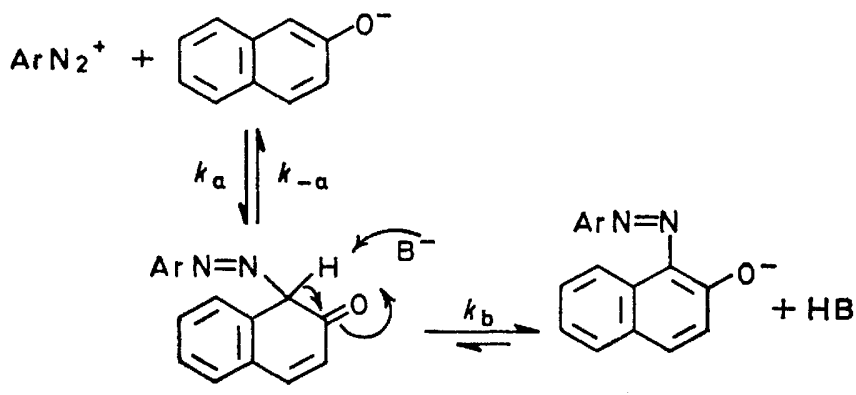

SсHеме $1 A-S_{\mathrm{E}} 2$ Mechanism for diazo-coupling with 2-naptholate ion

isotope effects for these reactions requires that assumptions be made about secondary isotope effects, so the data contain an undesirable element of uncertainty. Similar approximations are not required for diazocoupling, so examination of these reactions may provide more accurate insight into the dependence of primary deuterium isotope effects on the transition state symmetry for proton transfer to and from aromatic substrates, as demonstrated, for example, by Zollinger and his colleagues ${ }^{3}$ for hindered naphthols.

Diazo-coupling to indoles has not been extensively investigated, but examination of aromatic nitrosation reveals a striking similarity between naphthols and indoles towards weakly electrophilic reagents. 4 Further, Binks and $\operatorname{Ridd}^{5}$ have reported preliminary evidence for an $A-S_{\mathrm{E}} 2$ diazo-coupling mechanism for indole itself, although the kinetics were complex for most diazonium ions and the product yields low. These complexities may well arise from the incidence of 3,2-rearrangements, ${ }^{6}$ which can be avoided with 2 -alkylated indoles. Significantly, Binks and Ridd ${ }^{5}$ found a deuterium isotope effect of unity, which suggests that ratelimiting proton transfer from the Wheland intermediate may be observed only with sterically hindered indoles, as for naphthols.,7 Their studies, however, did not clearly examine or establish reaction via the indolyl anion, although subsequent investigations of both indole hydrogen exchange reactions ${ }^{8}$ and diazo-coupling to pyrroles ${ }^{9}$ suggest this pathway could be important at high $\mathrm{pH}$.

3 S. B. Hanna, C. Jermini, and H. Zollinger, Tetrahedron Letters, $1969,4415$.

4 R. J. Higgins, Ph.D. Thesis, London, 1972; also compare B. C. Challis and R. J. Higgins, J.C.S. Perkin II, 1973, 1597 ; B. C. Challis and A. J. Lawson, ibid., p. 918.

5 J. H. Binks and J. H. Ridd, J. Chem. Soc., 1957, 2398.

6 G. Castnati, A. Dossena, and A. Pochini, Tetrahedron Letters, 1972, 5227; R. Iyer, A. H. Jackson, P. V. R. Shannon, and B. Naidoo, J.C.S. Perkin II, 1973, 872; V. G. Avramenko, V. D. Nazina, L. A. Polyakova, and O. Y. Okhlobystin, Trudy Mosk. Khim. Teknol. Inst., 1970, 132.

7 F. Snychers and H. Zollinger, Tetrahedron Letters, 1970 2579; Helv. Chim. Acta, 1970, 53, 1294.
We have therefore examined the kinetics of diazocoupling of several 2-methylindoles under a wide range of experimental conditions. These establish the reaction mechanism unequivocally and ascertain factors influencing the observation of substantial primary deuterium isotope effects.

\section{EXPERIMENTAL}

Substrates.-2-Methylindole (Koch-Light) and 2-t-butylindole (synthesised according to Jönsson ${ }^{10}$ ) were purified by vacuum sublimation to give m.p. $57-58^{\circ}$ (lit., ${ }^{11} 59-60^{\circ}$ ) and $72-73^{\circ}$ (lit., ${ }^{10} 73-74^{\circ}$ ), respectively.

4-Methyl-2-t-butylindole was prepared by treating 2,3dimethylaniline with pivalolyl chloride and fusing the resultant anilide with $\mathrm{Bu}^{\mathrm{t}} \mathrm{OK} .{ }^{12}$ The yield was $60 \%$, m.p. $86^{\circ}$ (vacuum sublimed), $\nu_{\max }$ (Nujol-Kel-F) 3390 , $1589,1540,790,771$, and $698 \mathrm{~cm}^{-1}, \delta\left(\mathrm{CCl}_{4}\right) 1.33(9 \mathrm{H}, \mathrm{s})$, $2.52(3 \mathrm{H}, \mathrm{s}), 6.27(1 \mathrm{H}, \mathrm{d}, J 2.4 \mathrm{~Hz})$, and $7.0(3 \mathrm{H}, \mathrm{m})$ (Found: $\mathrm{C}, 83.4 ; \mathrm{H}, 9.2 ; \mathrm{N}, 7.5 . \mathrm{C}_{13} \mathrm{H}_{17} \mathrm{~N}$ requires $\mathrm{C}$, 83.4; H, 9.1; N, 7.5\%).

2-Methyl-4,6-di-t-butylindole.-3,5-Di-t-butylbenzoic acid was prepared from 3,5-di-t-butyltoluene after Geuze et al. ${ }^{13}$ and converted to 3,5 -di-t-butylaniline by treatment with $\mathrm{NaN}_{3}$ in $\mathrm{H}_{2} \mathrm{SO}_{4}{ }^{14}$ (Found: $\mathrm{C}, 82.0 ; \mathrm{H}, 11.1 ; \mathrm{N}, 6.6$. Calc. for $\mathrm{C}_{14} \mathrm{H}_{23} \mathrm{~N}$ : C, $81.9 ; \mathrm{H}, 11.3 ; \mathrm{N}, 6.8 \%$ ). 3,5-Di-tbutylaniline $(80 \mathrm{~g})$ in dry diglyme $(250 \mathrm{ml})$ was heated under reflux with freshly prepared $\mathrm{NaNH}_{2}(15 \mathrm{~g})$ until evolution of $\mathrm{NH}_{3}$ ceased, when 2-bromoacetaldehyde diethyl acetal ${ }^{15}(70 \mathrm{~g})$ was added dropwise. After heating under reflux for $1 \mathrm{~h}$, the solvent was removed and excess of $\mathrm{H}_{2} \mathrm{O}$ added. Ether extraction, followed by fractional vacuum distillation gave 2 -(3,5-di-t-butylanilino)acetaldehyde diethyl acetal $(30 \mathrm{~g})$, b.p. $122-130^{\circ}$ at 0.4 Torr, $m / e 335\left(M^{+}\right)$and $232(\mathrm{ArNH}=\mathrm{CHMe})$. Treatment this acetal with $\mathrm{BF}_{3}$ in benzene at $c a .25^{\circ}$ for $4 \mathrm{~h},{ }^{15}$ followed by addition of excess of $\mathrm{Et}_{3} \mathrm{~N}$, filtration, and removal of the solvent gave a thick oily residue. Chromatography on alumina (Merck Al) eluting with hexane-dichloromethane (10:90) gave 2-methyl-4,6-di-t-butylindole in $15 \%$ yield as the first eluted fraction, m.p. (from hexane) $172-173^{\circ}$, $v_{\max }$ (Nujol-hexachlorobutadiene) $3370,1617,1548,849$, 784 , and $755 \mathrm{~cm}^{-1}, \delta\left(\mathrm{CCl}_{4}\right) 1.35(9 \mathrm{H}, \mathrm{s}), 1.45(9 \mathrm{H}, \mathrm{s})$, $2.37(3 \mathrm{H}, \mathrm{s}), 6.27(1 \mathrm{H}, \mathrm{m}), 6.97(2 \mathrm{H}, \mathrm{s})$, and $7.4 \mathrm{br}(1 \mathrm{H}$, exchanges with $\left.\mathrm{D}_{2} \mathrm{O}\right), \lambda_{\max .}(50 \% \mathrm{w} / \mathrm{w}$ methanol) $223(\log \varepsilon$ 4.53) and $272 \mathrm{~nm}(3.95), m / e 243\left(M^{+}\right)$and $229\left(M^{+}-15\right)$ (Found: $\mathrm{C}, 83.7 ; \mathrm{H}, 10.3 ; \mathrm{N}, 5.8 . \mathrm{C}_{17} \mathrm{H}_{26} \mathrm{~N}$ requires $\mathrm{C}$, $83.8 ; \mathrm{H}, 10.4 ; \mathrm{N}, 5.8 \%$ ).

Labelled Indoles.-Deuteriation was effected by dissolving the substrate (ca. $500 \mathrm{mg}$ ) in $\mathrm{MeOD}$ (10 $\mathrm{ml}$ ) to which sodium metal ( $c a .500 \mathrm{mg}$ ) had been previously added and allowing to stand overnight. Vacuum evaporation of the solvent followed by addition of $\mathrm{H}_{2} \mathrm{O}$ precipitated

8 B. C. Challis and E. M. Millar, J.C.S. Perkin II, 1973, 1111. 9 K. Mitsumura, Y. Hashida, S. Sekiguchi, and K. Matsui, Bull. Chem. Soc. Japan, 1973, 46, 1770.

10 A. Jönsson, Svensk. kem. Tidskr., 1955, 67, 188.

11 N. B. Chapman, K. Clarke, and H. Hughes, J. Chem. Soc., $1965,1424$.

${ }_{12}$ T. F. Tyson, J. Amer. Chem. Soc., 1941, 63, 2024; L. Marion and C. W. Oldfield, Canad. J. Res., 1947, 25B, 1.

13 J. Geuze, C. Ruinard, J. Salterbrock, D. F. Verkade, and B. M. Wepster, Rec. trav. chim., 1956, 75, 301.

${ }_{14}$ T. W. Elder and R. P. Mariella, Canad. J. Chem., 1963, 41, 1653 .

${ }_{15}$ M. Chastrette, Ann. Chim., 1962, 7, 643. 
the product, which was filtered, dried, and purified by vacuum sublimation. Tritiation was effected similarly, using THO $\left(1 \mathrm{ml} ; 20 \mathrm{mCi} \mathrm{ml}^{-1}\right)$ in methanol $(10 \mathrm{ml})$.

Reagents.-Solutions of diazonium ions were prepared in two ways: by aqueous diazotisation of a standard solution of the corresponding amine ${ }^{16}$ (reagent grade material purified by vacuum sublimation) or from the solid diazonium tetrafluoroborate (prepared according to Sakigara and Kikuchi, ${ }^{17}$ and recrystallised repeatedly from acetone by the addition of hexane). Diazonium ion concentrations in solution were checked by their absorbance at $c a .280 \mathrm{~nm}$, and the two methods gave close agreement.

Reagent grade dioxan (B.D.H.) was used without purification other than passage through a fresh Merck $\mathrm{Al}$ alumina column to remove peroxides. Deuterium oxide (N.m.r. Ltd; 99.7\%) was used as supplied. Buffer solutions were prepared from AnalaR materials and their
$525 \mathrm{~nm}$ (for the 2-methyl-4,6-di-t-butyl derivative)]. All measurements were taken with the reaction solution contained in a thermojacketted cell at $25 \pm 0.1^{\circ}$ using a Unicam SP 1800 spectrophotometer. Control experiments established the spontaneous decomposition rate of the diazonium ion under the coupling conditions and a small correction was applied where necessary. The final (' infinity ') absorption of the reaction solution was normally within $5 \%$ of its calculated value from the extinction coefficient of the purified product, although slow reactions showed lower values.

Several experiments employed the ' R-salt' method ${ }^{16}$ and gave good agreement with a direct spectrophotometric assay of the reaction solutions.

Simultaneous measurement of diazo-deprotonation and -detritiation rates required a modified technique. Here, at least a 10-fold excess of diazonium ion over indole was used

TABLE 1

Physical data for 2,4,6-trisubstituted 3-arylazoindole hydrotetrafluoroborates

\begin{tabular}{|c|c|c|c|c|c|c|c|}
\hline 3-Aryl & 2-Subst & 4-Subst & 6-Subst & $M$ & $v_{\max } / \mathrm{cm}^{-1}$ & Chemical shift $(\delta)$ & $\lambda_{\max } / \mathrm{nm}(\log \varepsilon)$ \\
\hline$p-\mathrm{MeC}_{6} \mathrm{H}_{4}$ & $\mathrm{Me}$ & $\mathrm{H}$ & $\mathrm{H}$ & 249 & $\begin{array}{l}3220,1603,1550 \\
830,760,750\end{array}$ & $\begin{array}{l}2.37(3 \mathrm{H}, \mathrm{s}), 2.77(3 \mathrm{H}, \mathrm{s}), 7.2-7.8 \\
(7 \mathrm{H}, \mathrm{m}), 8.42(1 \mathrm{H}, \mathrm{m}), 11.7 \mathrm{br}(2 \mathrm{H})\end{array}$ & $\begin{array}{l}282(4.02) \\
377(4.34)\end{array}$ \\
\hline$p-\mathrm{MeC}_{6} \mathrm{H}_{4}$ & $\mathrm{Bu}^{\mathrm{t}}$ & $\mathrm{Me}$ & $\mathrm{H}$ & 305 & & $\begin{array}{l}1.75(9 \mathrm{H}, \mathrm{s}), 2.47(3 \mathrm{H}, \mathrm{s}), 2.83(3 \mathrm{H}, \mathrm{s}) \\
\quad 7.32-7.80(7 \mathrm{H}, \mathrm{m})\end{array}$ & \\
\hline$p-\mathrm{MeC}_{6} \mathrm{H}_{4}$ & $\mathrm{Me}$ & $\mathrm{Bu}^{\mathrm{t}}$ & $B u^{t}$ & 361 & $\begin{array}{l}3300,1630,1608 \\
1062,878,809\end{array}$ & $\begin{array}{l}1.35, \mathrm{I} .57(18 \mathrm{H}, \mathrm{d}), 2.34(3 \mathrm{H}, \mathrm{s}), 2.65 \\
\quad(3 \mathrm{H}, \mathrm{s}), 7.18(2 \mathrm{H}, \mathrm{s}), 7.2-7.7(2 \mathrm{H}, \mathrm{dd}, \\
J 8.2 \mathrm{~Hz})\end{array}$ & $\begin{array}{l}289(4.14) \\
401(4.19)\end{array}$ \\
\hline$p-\mathrm{MeOC}_{6} \mathrm{H}_{4}$ & $\mathrm{Me}$ & $\mathrm{Bu}^{\mathrm{t}}$ & $B u^{t}$ & 377 & $\begin{array}{l}3270,1601,1060 \text {, } \\
875,840\end{array}$ & $\begin{array}{l}1.34,1.55(18 \mathrm{H}, \mathrm{d}), 2.61(3 \mathrm{H}, \mathrm{s}), 3.78 \\
\quad(3 \mathrm{H}, \mathrm{s}), 6.98-7.72(4 \mathrm{H}, \mathrm{dd}, J 9 \mathrm{~Hz}) \\
\quad 7.14(2 \mathrm{H}, \mathrm{s})\end{array}$ & $\begin{array}{l}289(4.16) \\
401(4.22)\end{array}$ \\
\hline
\end{tabular}

TABle 2

Analytical data for 2,4,6-trisubstituted 3-arylazoindole hydrotetrafluoroborates

\begin{tabular}{|c|c|c|c|c|c|c|c|c|}
\hline 3-Aryl & 2-Subst & 4-Subst & 6-Subst & Formula & & $\mathrm{C}(\%)$ & $\mathrm{H}(\%)$ & $\mathrm{N}(\%)$ \\
\hline \multirow{2}{*}{$p-\mathrm{MeC}_{6} \mathrm{H}_{4}$} & $\mathrm{Me}$ & $\mathrm{H}$ & $\mathrm{H}$ & $\mathrm{C}_{16} \mathrm{H}_{16} \mathrm{~N}_{3} \mathrm{BF}_{4}$ & Found & 57.1 & 4.95 & 12.25 \\
\hline & & & & & Required & 57.0 & 4.8 & 12.45 \\
\hline \multirow{2}{*}{$p-\mathrm{MeC}_{6} \mathrm{H}_{4}$} & $\mathrm{Bu}^{\mathrm{t}}$ & $\mathrm{Me}$ & $\mathrm{H}$ & $\mathrm{C}_{20} \mathrm{H}_{24} \mathrm{~N}_{3} \mathrm{BF}_{4}$ & Found & 61.05 & 6.2 & 10.85 \\
\hline & & & & & Required & 61.1 & 6.15 & 10.7 \\
\hline$p-\mathrm{MeC}_{6} \mathrm{H}_{4}$ & $\mathrm{Me}$ & $\mathrm{Bu}^{\mathrm{t}}$ & $\mathrm{Bu}^{\mathrm{t}}$ & $\mathrm{C}_{24} \mathrm{H}_{32} \mathrm{~N}_{3} \mathrm{BF}_{4}$ & Found & 64.45 & 7.2 & 9.4 \\
\hline \multirow{2}{*}{$p-\mathrm{MeOC}_{6} \mathrm{H}_{4}$} & $\mathrm{Me}$ & $\mathrm{Bu}^{\mathrm{t}}$ & $\mathrm{Bu}^{\mathrm{t}}$ & $\mathrm{C}_{24} \mathrm{H}_{32} \mathrm{~N}_{3} \mathrm{OIBF}_{4}$ & Found & $\begin{array}{l}\text { 64.15 } \\
61.9\end{array}$ & $\begin{array}{l}1.15 \\
6.95\end{array}$ & $\begin{array}{l}9.35 \\
8.95\end{array}$ \\
\hline & & & & & Required & 61.95 & 6.95 & 9.0 \\
\hline \multirow[t]{2}{*}{$p-\mathrm{NO}_{2} \mathrm{C}_{8} \mathrm{H}_{4}$} & $\mathrm{Me}$ & $\mathrm{Bu}^{\mathrm{t}}$ & $\mathrm{Bu}^{\mathrm{t}}$ & $\mathrm{C}_{23} \mathrm{H}_{29} \mathrm{~N}_{4} \mathrm{O}_{2} \mathrm{BF}_{4}$ & Found & 57.4 & 6.05 & 11.65 \\
\hline & & & & & Required & 57.5 & 6.1 & 11.65 \\
\hline
\end{tabular}

$\mathrm{pH}$ measured on a Radiometer $26 \mathrm{pH}$ meter using a G202B glass electrode (calibrated with standard aqueous buffers).

Products.-These were prepared by the addition of a solution of the indole $(c a .11 \mathrm{mmol})$ in acetone $(10 \mathrm{ml})$ to the arenediazonium tetrafluoroborate $(c a .10 \mathrm{mmol})$ also in acetone $(10 \mathrm{ml})$. After $20 \mathrm{~min}$, hexane was added dropwise to precipitate the tetrafluoroborate of the azoindole. Absence of n.m.r. bands attributable to 3-H confirmed the site of the substitution in all cases. Confirmatory physical and analytical data are given in Tables 1 and 2 respectively.

Kinetics.-Rates of diazo-coupling at $\mathrm{pH} \geqslant 3.5$ were normally measured by u.v. assay of the reaction solution at the absorption maximum of the product $\left(\lambda_{\max } 377-401\right.$ $\mathrm{nm})$. Coupling rates in dilute acid $(\mathrm{pH}<1)$ were followed similarly at the absorption maximum of the protonated 3 -azoindole $\left[\lambda_{\max } 445\right.$ (for the 2-methyl derivative) and

16 V. Machacek, O. Machackova, and V. Sterba, Coll. Czech. Chem. Comm., 1971, 36, 3186.

17 M. Sukigara and S. Kikuchi, Bull. Chem. Soc. Japan, 1967, 40, 1077. and the reaction solutions were buffered to $\mathrm{pH} 7.3-7.8$ to minimise both solvent-catalysed protodetritiation and homolytic decomposition of the diazonium ion ${ }^{18}$ and products. ${ }^{19}$ The kinetic runs were initiated by adding the $\left[3-{ }^{3} \mathrm{H}_{1}\right]$ indole (ca. $1 \mathrm{mg}$ in $0.5 \mathrm{ml}$ dioxan) to the reaction solution $(100 \mathrm{ml})$ in a volumetric flask. One portion was transferred to the thermojacketted spectrophotometer cell for continuous u.v. assay, whereas others $(10 \mathrm{ml})$ were removed at timed intervals and their reaction quenched by shaking with xylene $(15 \mathrm{ml})$. A portion of the xylene fraction (containing the indole substrate and product) was taken and air was passed through it for $c a .15$ min to clear the solution and remove traces of THO. Radiometric assay was made with a Beckmann LS200 liquid scintillation counter, calibrated beforehand for the extensive quenching induced by the arylazoindole.

18 P. Burri, H. Loewenschuss, H. Zollinger, and G. K. Zwolinski, Helv. Chim. Acta, 1974, 57, 395 .

19 (a) N. N. Bubnov, K. A. Bilevitch, L. A. Polyakova, and O. Y. Okhlobystin, J.C.S. Chem. Comm., 1972, 1058; (b) S. McLean and G. I. Dmitrienko, Canad. J. Chem., 1971, 49, 3642. 
Generally, diazodedeuteriation was examined in $\mathrm{H}_{2} \mathrm{O}$ solvents and control experiments established that solventcatalysed exchange of the substrate was negligible during the duration of the kinetic run. Where this condition was not met, $\mathrm{D}_{2} \mathrm{O}$ was used instead of $\mathrm{H}_{2} \mathrm{O}$.

Calculation of Rate Coefficients.-All pseudo-first-order rate coefficients were evaluated by means of equations (I) or (2), where $a$ and $x$ refer to the final and transient

$$
\begin{aligned}
& x=a-\mathrm{e}^{-\left(k_{0} t+b\right)} \\
& x=a+\mathrm{e}^{-\left(k_{0} t+b\right)}
\end{aligned}
$$

(at time $=t$ ) concentrations of the azoindole product in equation ( 1 ) or to the final and transient concentrations of the reactant in equation (2). Both expressions were treated by a non-linear least squares weighted regression method ${ }^{20}$ to derive values $k_{0}$ and their standard errors. Data in Table 3 and 4 illustrate this analysis for the two

\section{TABLE 3}

Simultaneous diazo-deprotonation and -detritiation of 2 methylindole in $40 \%(\mathrm{v} / \mathrm{v})$ aqueous dioxan at $\mathrm{pH} \mathbf{7 . 8 1}$ and $25^{\circ}$. Initial $\left[p-\mathrm{MeOC}_{6} \mathrm{H}_{4} \mathrm{~N}_{2}{ }^{+}\right] 5 \times 10^{-3} \mathrm{M}$; initial

\begin{tabular}{|c|c|c|c|c|}
\hline \multirow[b]{2}{*}{$t / \min$} & \multicolumn{2}{|c|}{ Diazodeprotonation } & \multicolumn{2}{|c|}{ Diazodetritiation } \\
\hline & $\begin{array}{c}\text { O.D. } \\
(380 \mathrm{~nm})\end{array}$ & $\begin{array}{l}\text { O.D. } \\
\text { (calc.) }\end{array}$ & C.p.m. & $\begin{array}{l}\text { C.p.m. } \\
\text { (calc.) }\end{array}$ \\
\hline 0 & 0.089 & 0.087 & 8162 & 8231 \\
\hline 1 & 0.140 & 0.143 & & \\
\hline 2 & 0.195 & 0.195 & & \\
\hline 3 & 0.242 & 0.242 & 6272 & 6726 \\
\hline 4 & 0.286 & 0.285 & & \\
\hline 6 & 0.361 & 0.361 & 4815 & 4774 \\
\hline 8 & 0.425 & 0.425 & & \\
\hline 10 & 0.479 & 0.478 & 3341 & 3325 \\
\hline 12 & 0.525 & 0.523 & & \\
\hline 14 & 0.562 & 0.561 & 2309 & 2319 \\
\hline 18 & 0.621 & 0.619 & 1643 & 1621 \\
\hline 22 & 0.660 & 0.660 & 1113 & 1137 \\
\hline 28 & & & 679 & 674 \\
\hline$\infty$ & 0.750 & $0.757 \pm 0.004$ & 40 & $40 \pm 28$ \\
\hline
\end{tabular}
(2-methylindole) $\mathrm{ca} .4 \times 10^{-5} \mathrm{M}$

principal methods of following the diazo-coupling rates. The accuracy of the rate constants was estimated to be better than $\pm 6 \%$.

Observed isotopic rate ratios $\left(k^{\mathrm{H}} / k^{\mathrm{D}}\right)_{0}$ were corrected for the isotopic purity of the deuteriated substrate (containing atom fraction of $\left[{ }^{2} \mathrm{H}_{1}\right]=n$ ) by means of equation (3).

$$
k^{\mathrm{H}} / k^{\mathrm{D}}=\left(k^{\mathrm{H}} / k^{\mathrm{D}}\right)_{0} n /\left[1-\left(k^{\mathrm{H}} / k^{\mathrm{D}}\right)_{0}(1-n)\right]
$$

The isotopic purity was determined by mass spectrometric assay.

\section{RESULTS}

2-Methylindole.-Coupling with toluene-p-diazonium chloride or tetrafluoroborate between $\mathrm{pH} 7$ and -1 in $20 \%$ $(\mathrm{v} / \mathrm{v})$ dioxan at $25^{\circ}$ was quantitative $(>95 \%)$. At higher

* Stoicheiometric reactant concentrations are denoted by round brackets and actual reactant concentrations by square brackets. Differences in the two are significant at certain $\mathrm{pH}$ because of prototropic equilibria. Thus $[\mathrm{InH}],\left[\mathrm{InH}_{2}+\right]$, and $\left[\mathrm{In}^{-}\right]$denote actual concentrations of the neutral substrate, its conjugate acid, and base, respectively, whereas (Indole) represents the sum of all three. Rate coefficients dependent on stoicheiometric concentrations are denoted by a superscript bar.
$\mathrm{pH}$, however, the product yield dropped to $c a .50 \%$, probably due to several adverse factors such as homolysis of the product, ${ }^{19} a$ radical oxidation of 2 -methylindole, ${ }^{19 b}$ and homolytic decomposition of the diazonium ion reagent. ${ }^{18}$

\section{TABLE 4}

Diazo-coupling of 2-methyl-4,6-di-t-butylindole in $40 \%$ $(\mathrm{v} / \mathrm{v})$ aqueous dioxan at $\mathrm{pH} 4$ and $25^{\circ}$. Initial $[p-$ $\mathrm{MeOC}_{6} \mathrm{H}_{4} \mathrm{~N}_{2}^{+}$] $4 \times 10^{-5} \mathrm{M} ;$ [2-methyl-4,6-di-t-butylindole $4 \times 10^{-4} \mathrm{M}$

$\begin{array}{rccc}t / \mathrm{s} & \begin{array}{c}\text { Reaction } \\ (\%)\end{array} & \begin{array}{c}\text { O.D. } \\ (401 \mathrm{~nm})\end{array} & \begin{array}{c}\text { O.D. } \\ (\mathrm{calc})\end{array} \\ 0 & 0 & & 0.005 \\ 50 & 6.4 & 0.060 & 0.064 \\ 100 & 12.5 & 0.121 & 0.120 \\ 150 & 18.1 & 0.179 & 0.172 \\ 200 & 23.4 & 0.222 & 0.221 \\ 300 & 32.9 & 0.308 & 0.309 \\ 400 & 41.3 & 0.385 & 0.386 \\ 500 & 48.7 & 0.451 & 0.454 \\ 600 & 55.1 & 0.511 & 0.513 \\ 800 & 65.5 & 0.610 & 0.610 \\ 1000 & 73.7 & 0.686 & 0.685 \\ 1250 & 81.2 & 0.758 & 0.754 \\ 1750 & 90.2 & 0.838 & 0.838 \\ 2000 & 93.1 & 0.861 & 0.864 \\ \infty 0 & & 0.930 & 0.925 \pm 0.004 \\ & & & \end{array}$

Zollinger ${ }^{18}$ has suggested that the latter is exacerbated by electron-withdrawing aryl substituents, and, indeed, improved product yields (ca. $85 \%$ ) were found even at $\mathrm{pH} 11$ for $p$-methoxybenzenediazonium salts.

Kinetic Orders.-The $A-S_{\mathrm{E}} 2$ mechanism requires that the rate of coupling at constant $\mathrm{pH}$ follows equation (4)

$$
\text { Rate }=\tilde{k}_{2} \text { (Indole) }\left[\mathrm{ArN}_{2}{ }^{+}\right]
$$

which, of course, reduces to equation (5) when the substrate is in large excess. Except for the very slowest reactions $\left(t_{\frac{1}{2}}>10^{3} \mathrm{~s}\right)$, the kinetic data followed equation (5) to

$$
=k_{0}\left[\mathrm{ArN}_{2}^{+}\right]
$$

greater than $90 \%$ reaction, as shown by the typical experiment cited in Table 3 . For coupling to toluene-p-diazonium

TABLE 5

Diazodeprotonation of 2-methylindole in $20 \%(\mathrm{v} / \mathrm{v})$ aqueous dioxan at $\mathrm{pH} 3.5 \pm 0.3$ and $27.5^{\circ}$. Initial $\left[p-\mathrm{MeC}_{6} \mathrm{H}_{4} \mathrm{~N}_{2}^{+}\right] 10^{-4} \mathrm{M}$

$\begin{array}{ccc}10^{3}[\operatorname{InH}] / \mathrm{M} & 10^{3} k_{0} / \mathrm{s}^{-1} & k_{2} / 1 \mathrm{~s}^{-1} \mathrm{~mol}^{-1} \\ 5.5 & 11.5 & 2.09 \\ 4.0 & 8.16 & 2.08 \\ 3.0 & 6.45 & 2.14 \\ 2.0 & 4.20 & 2.10 \\ 1.4 & 3.03 & 2.16 \\ 0.5 & 0.97 & 1.95 \\ 0.25^{a} & 0.52 & 2.08 \\ 0.1^{b} & & 1.9 \\ 1.0^{c} & 1.58 & 1.58 \\ 0.1^{d} & & 1.55\end{array}$

$a\left[p-\mathrm{MeC}_{\mathrm{d}} \mathrm{H}_{4} \mathrm{~N}_{2}+\mathrm{Cl}-\right]=2.5 \times 10^{-5} \mathrm{M} . \quad{ }^{b}$ Equimolar concentrations. ${ }^{\circ}$ Followed by $\mathrm{R}$-salt method, $0 \%$ dioxan. ${ }^{d}$ Equimolar concentration, $\mathrm{R}$-salt method, $0 \%$ dioxan.

20 W. E. Deming, 'Statistical Adjustment of Data,' Wiley, New York, 1943; W. E. Wentworth, J. Chem. Educ., 1965, 42, 96, 162. 
chloride in phthalate buffers (pH $3.5 \pm 0.3$ ), evidence in Table 5 shows that $\bar{k}_{2}$ is independent of (Indole) so the validity of equation (4) is established. Further, a consistent value for $\bar{k}_{2}$ is obtained from the reaction with equimolar reactant concentrations. Other data listed in Table 5 obtained by the ' $R$-salt' method in purely aqueous phthalate buffers show that addition of $20 \%$ dioxan has only a small effect on the reaction rate.

Acidity Dependence.-Because 2-methylindole is both a weak base $\left(\mathrm{p} K_{\mathrm{A}}-0.3\right){ }^{21}$ and a weak acid $\left(\mathrm{p} K_{\mathrm{E}} c a .17\right),{ }^{22} \bar{k}_{2}$ should be acidity dependent outside the $\mathrm{pH}$ range $1-7$ with reaction proceeding via either the neutral or conjugate base species. The potential pathways to products allowing for the: prototropic equilibria are summarised in Scheme 2.

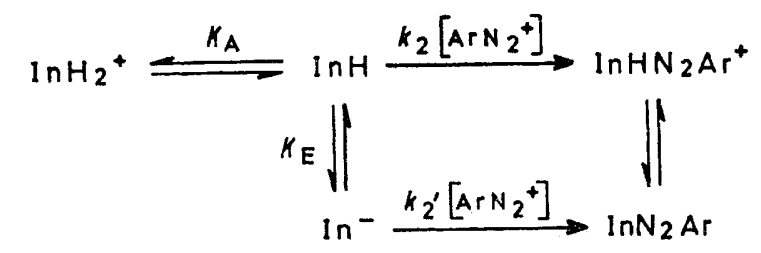

SCHEMe 2 Reaction pathways for diazo-coupling to indoles

The stoicheiometric coefficient $\bar{k}_{2}$ is related to the molecular coefficients for reaction via the neutral molecule $\left(k_{2}\right)$ and the indolyl anion $\left(k_{2}{ }^{\prime}\right)$ by equation (6). Within the $\mathrm{pH}$ range $1-7, \bar{k}_{2}=k_{2}$ (because $K_{\mathrm{A}} \gg\left[\mathrm{H}_{3} \mathrm{O}^{+}\right] \gg K_{\mathrm{E}}$ ), but at other

$$
\bar{k}_{2}=\frac{k_{2}+k_{2}{ }^{\prime}\left(K_{\mathrm{E}} /\left[\mathrm{H}_{3} \mathrm{O}^{+}\right]\right)}{\left[\mathrm{H}_{3} \mathrm{O}^{+}\right] / K_{\mathrm{A}}+\mathrm{I}+K_{\mathrm{E}} /\left[\mathrm{H}_{3} \mathrm{O}^{+}\right]}
$$

$\mathrm{pH}$ values the molecular rate coefficients are conveniently evaluated from limiting equations.

Thus, at $\mathrm{pH}<1$, where reaction via the indolyl anion is negligible, equation (6) reduces to $(7)$. The rate of coupling

$$
\left[\mathrm{H}_{3} \mathrm{O}^{+}\right]=k_{2} K_{\mathrm{A}} / k_{2}-K_{\mathrm{A}}
$$

with $p$-toluenediazonium chloride was measured in $\mathrm{HCl}$ at constant ionic strength and the relevant plot of $\mathrm{I} / \bar{k}_{2}$ versus $\left[\mathrm{H}_{3} \mathrm{O}^{+}\right]$shown in Figure 1 gives $k_{2} c a .2 .1 \mathrm{l} \mathrm{mol}^{-1} \mathrm{~s}^{-1}$ and $\mathrm{p} K_{\mathrm{A}}-0.14$ at ionic strength of 2.0. Thus $k_{2}$ agrees well with that obtained in phthalate buffers (Table 5) which, in turn, suggests that base catalysis by phthalate ion is not significant. The $\mathrm{p} K_{\mathrm{A}}$ is slightly different from that reported for pure $\mathrm{H}_{2} \mathrm{O}\left(\mathrm{p} K_{\mathrm{A}}-0.30\right),{ }^{21}$ probably a consequence of deviation between the $h_{\mathrm{I}}$ acidity function ${ }^{21}$ and $\left[\mathrm{H}_{3} \mathrm{O}^{+}\right]$with high $\mathrm{HCl}$ concentrations. This deviation would also account for the non-linearity observed in Figure 1 at high [HCl].

In mildly alkaline solution $(12>\mathrm{pH}>9)$ reaction of the indolyl anion becomes important, despite its low concentration. Here, $K_{\mathrm{E}} \ll\left[\mathrm{H}_{3} \mathrm{O}^{+}\right]$and $K_{\mathrm{A}} \gg\left[\mathrm{H}_{3} \mathrm{O}^{+}\right]$so the kinetic expression approximates to equation (8).* Accurate

$$
k_{2}=k_{2}+k_{2}^{\prime} K_{\mathrm{E}} /\left[\mathrm{H}_{3} \mathrm{O}^{+}\right]
$$

measurement of coupling rates at this $\mathrm{pH}$ was possible only for $p$-methoxybenzenediazonium salts, and a plot of the relevant data (Figure 2) gives values of $k_{2} 0.381 \mathrm{~mol}^{-1} \mathrm{~s}^{-1}$

* Equation (8) is valid only where conversion of the arenediazonium ion into the corresponding arenediazohydroxide is insignificant, as in the present studies. and $k_{2}{ }^{\prime} K_{\mathrm{E}} 7 \times 10^{10} \mathrm{~s}^{-1}$. Since $K_{\mathrm{E}} c a \cdot 10^{-17} \mathrm{l}^{-1} \mathrm{~mol}$ for 2 -methylindole in aqueous solution, ${ }^{22}$ to a good approximation $k_{2}^{\prime} c a .7 \times 10^{7} 1 \mathrm{~mol}^{-1} \mathrm{~s}^{-1}$. The rate ratio for diazocoupling to the 2 -methylindolyl anion relative to the neutral substrate $k_{2}{ }^{\prime} / k_{2}$ ca. $2 \times 10^{8}$.

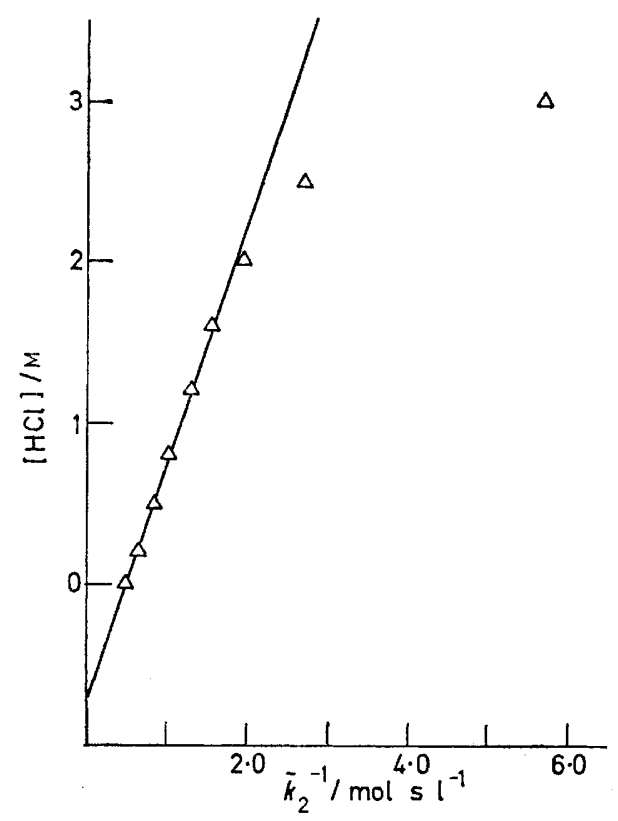

FIGURE 1 Acidity dependence of the rate of diazodeprotonation of 2 -methylindole in dilute $\mathrm{HCl}$ at $25^{\circ}$

Activation Parameters.-The rate of coupling of $p$ toluenediazonium chloride in aqueous phthalate buffers ( $\mathrm{pH} 3.0 \pm 0.05)$ was also examined at several temperatures

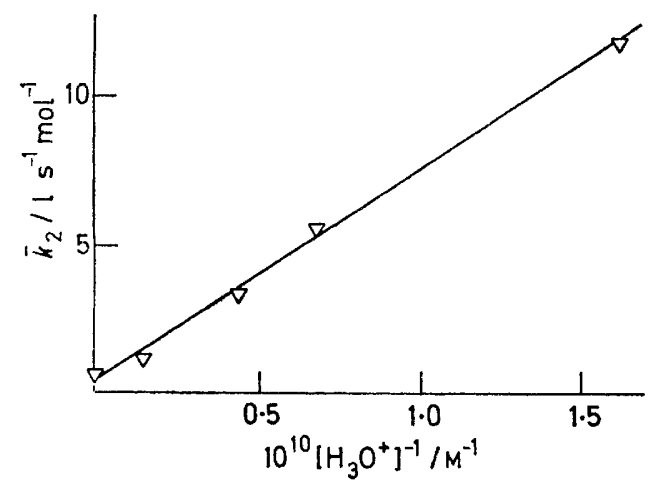

FIGURE 2 Rate of diazodeprotonation of 2-methylindole with $p$-methoxybenzenediazonium ion at high $\mathrm{pH}$ and $25^{\circ}$

from 0 to $35.4^{\circ}$ and these data are listed in Table 6 . From a satisfactory linear plot of $\log \widetilde{k}_{2} / T$ versus $1 / T$ values of $\Delta H^{\ddagger}=38 \mathrm{~kJ} \mathrm{~mol}{ }^{-1}$ and $\Delta S^{\ddagger}=-138 \mathrm{~J} \mathrm{~K}^{-1} \mathrm{~mol}^{-1}$ were obtained.

Hydrogen Isotope Effects.-Isotopic rate ratios for

21 R. L. Hinman and J. Lang, J. Amer. Chem. Soc., 1964, 86, 3796.

${ }_{22}$ G. Yagil, J. Phys. Chem., 1967, 71, 1034, 1045; Tetrahedron, $1967,23,2855$. 
coupling of the diazonium salt with the neutral 2-methylindole and its $\left[3-{ }^{2} \mathrm{H}_{1}\right]$ isomer $\left(k_{2} \mathrm{H} / k_{2} \mathrm{D}\right)$ and their corresponding anions $\left(k_{2}{ }^{\prime} / k_{2}{ }^{\prime}\right)$ were both found to be $1.0 \pm 0.2$, showing the same behaviour as indole itself. ${ }^{5}$ The corresponding

\section{TABLE 6}

Temperature dependence of the rate of diazodeprotonation of 2-methylindole in $\mathrm{H}_{2} \mathrm{O}$ at $\mathrm{pH} 3.0 \pm 0.5$. Initial $\left[p-\mathrm{MeC}_{6} \mathrm{H}_{4} \mathrm{~N}_{2}^{+}\right] 10^{-4} \mathrm{M}$; (2-Methylindole) $10^{-3} \mathrm{M}$

$\begin{array}{cc}T /{ }^{\circ} \mathrm{C} & \kappa_{2} / 1 \mathrm{~s}^{-1} \mathrm{~mol}^{-1} \\ 0 & 0.365 \\ 5 & 0.508 \\ 10 & 0.679 \\ 17.5 & 1.05 \\ 25 & 1.54 \\ 30 & 2.15 \\ 35.4 & 3.22\end{array}$

tritium isotope effect (as shown in Table 3) was also unity. Together with the absence of significant base catalysis in phthalate buffers noted above, this implies that attack of the electrophilic diazonium ion, rather than proton loss from the Wheland intermediate, is fully rate limiting. This conclusion is borne out by the activation parameters given above which are significantly different from those found for isotopic hydrogen exchange $\left(\Delta H^{\ddagger} \mathrm{ca} .80 \mathrm{~kJ} \mathrm{~mol}^{-1}, \Delta S^{\dagger}\right.$ $\left.-16 \mathrm{~J} \mathrm{~K}^{-1} \mathrm{~mol}^{-1}\right) .{ }^{23}$

Hammett Relationship.-Apart from the p-methyl and $p$-methoxy-substituents noted above, coupling rates to the neutral 2-methylindole were also measured for other parasubstituted benzenediazonium ions in $20 \%(\mathrm{v} / \mathrm{v})$ aqueous dioxan at $\mathrm{pH} 4 \pm 0.3$. These data are summarised in Table 7 together with relevant values of $\sigma^{+}$parameters. The corresponding Hammett $\left(\rho \sigma^{+}\right)$plot is linear giving ค 3.3 (s $0.200 ; r 0.989)$.

\section{TABLE 7}

Coupling rates of 2-methylindole with para-substituted benzenediazonium ions in $20 \%(\mathrm{v} / \mathrm{v})$ aqueous dioxan at $25^{\circ}$

$\begin{array}{ccc}\text { Substituent } & \bar{k}_{2} / 1 \mathrm{~s}^{-1} \mathrm{~mol}^{-1} & \sigma_{p}{ }^{+} \\ \mathrm{MeO} & 0.37 & -0.27 \\ \mathrm{Me} & 1.8 & -0.17 \\ \mathrm{H} & 9.2 & 0.0 \\ \mathrm{Cl} & 31 & 0.23 \\ \mathrm{NO}_{2}{ }^{a} & 2700 & 0.78\end{array}$

a Extrapolated to $25^{\circ}$ from $3^{\circ}$ using the activation parametcrs given in text.

2-t-Butyl- and 4-Methyl-2-t-butylindole.-For these compounds measurements were limited to coupling rates of either toluene- $p$ - or $p$-methoxybenzene-diazonium salts with the neutral indoles (sce Table 8 ) principally to examine the effect of modest steric hindrance on their isotopic rate ratios. The results are summarised by three main observations. (a) 2-t-Butylindole couples at about half the rate of 2-methylindole, a difference entirely explicable in terms of the slightly reduced reactivity of the 2-t-butyl compound. ${ }^{24}(b)$ The 4-methyl group has no significant effect on the coupling so steric and reactivity perturbations either cancel or both are negligible. (c) The deuterium isotope effect is negligible $\left(\vec{k}_{2} \mathrm{H} / \vec{k}_{2} \mathrm{D} \quad 1.0 \pm 0.2\right)$ so proton removal from the Wheland intermediate remains relatively rapid. All three findings clearly imply that steric requirements for substitution by the diazonium ion are small.
2-Methyl-4,6-di-t-butylindole.-Yields of azo-product here were normally better than $90 \%$ irrespective of the relative reactant concentrations up to $\mathrm{pH}$ ca. 9. Above this $\mathrm{pH}$, excess of diazonium salt induced rapid autocatalytic decomposition of the product, but satisfactory yields and

TABLE 8

Diazo-coupling of 2-t-butyl- and 4-methyl-2-t-butyl-indole in $\mathrm{H}_{2} \mathrm{O}$ at $\mathrm{pH} \quad 4.0 \pm 0.6$ and $25^{\circ}$. Initial $[p-$ $\left.\mathrm{MeC}_{6} \mathrm{H}_{4} \mathrm{~N}_{2}^{+}\right]=10^{-4} \mathrm{M} . \quad$ (Indole) $=10^{-3} \mathrm{M}$

\begin{tabular}{|c|c|c|c|}
\hline Indole & Method & $\begin{array}{c}\text { Dioxan } \\
(\%)\end{array}$ & $\begin{array}{c}\bar{k}_{2} / \\
\mathrm{ls}^{-1} \mathrm{~mol}^{-1}\end{array}$ \\
\hline $2-\mathrm{Bu}^{t}$ & $376 \mathrm{~nm}$ & 20 & 0.750 \\
\hline $2-\mathrm{Bu}^{\mathrm{t}}$ & $376 \mathrm{~nm}$ & 20 & 0.792 \\
\hline $2-\mathrm{Bu}^{t}$ & R-Salt & 8 & 0.811 \\
\hline $2-\mathrm{Bu}^{\mathrm{t}}$ & $380 \mathrm{~nm}$ & 20 & $0.188^{a}$ \\
\hline $2-\mathrm{Bu}^{\mathrm{t}}-3-{ }^{2} \mathrm{H}_{1}$ & $376 \mathrm{~nm}$ & 20 & 0.790 \\
\hline $2-\mathrm{Bu}^{\mathrm{t}-3}-{ }^{2} \mathrm{H}_{1}$ & $376 \mathrm{~nm}$ & 20 & 0.823 \\
\hline $4-\mathrm{Me}-2-\mathrm{Bu}^{\mathrm{t}}$ & $384 \mathrm{~nm}$ & 40 & $0.737^{b}$ \\
\hline $4-\mathrm{Me}-2-\mathrm{Bu}^{t}$ & $384 \mathrm{~nm}$ & 40 & 0.677 \\
\hline $4-\mathrm{Me}-2-\mathrm{Bu}^{\mathrm{t}}-3-{ }^{2} \mathrm{H}_{1}$ & $384 \mathrm{~nm}$ & 40 & $0.65 \mathrm{i}$ \\
\hline $4-\mathrm{Me}-2-\mathrm{Bu}^{\mathrm{t}}-3-{ }^{2} \mathrm{H}_{1}$ & $384 \mathrm{~nm}$ & 40 & 0.683 \\
\hline
\end{tabular}

kinetics could be obtained up to $\mathrm{pH} 11$ with an excess of the indole.

The kinetic form of the reaction with $p$-methoxybenzenediazonium salts was examined under pseudo-first-order conditions with an excess of either the indole or the diazonium salt. For coupling at $\mathrm{pH} 4$ (phthalate buffers) in $40 \%(\mathrm{v} / \mathrm{v})$ aqueous dioxan (to solubilise the substrate), it is clear from Table 9 that equation (4) is followed. The

\section{TABLE 9}

Kinetic orders for diazodeprotonation of 2-methyl-4,6-di-tbutylindole in $40 \%(\mathrm{v} / \mathrm{v})$ aqueous dioxan at $\mathrm{pH} 4$ and $25^{\circ}$

\begin{tabular}{|c|c|c|c|}
\hline $10^{5}[$ Substrate $] / \mathrm{M}$ & $\underset{M}{\left.10^{5}\left[p-\mathrm{MeOC}_{6} \mathrm{H}_{4} \mathrm{~N}_{2}+\right]\right]}$ & $\begin{array}{c}10^{3} k_{0} / \\
\mathrm{s}^{-1}\end{array}$ & $\begin{array}{c}k_{2} / \\
1 \mathrm{~s}^{-1} \mathrm{~mol}^{-1}\end{array}$ \\
\hline 40 & 4 & 1.33 & 3.3 \\
\hline 40 & 4 & 1.28 & 3.2 \\
\hline 80 & 4 & 2.46 & 3.1 \\
\hline 4 & 35 & 1.19 & 3.4 \\
\hline 4 & 70 & 2.28 & 3.3 \\
\hline 4 & 140 & 4.51 & 3.2 \\
\hline 2 & 68 & 2.71 & $4.0^{*}$ \\
\hline 100 & 10 & 0.36 & $0.36 \dagger$ \\
\hline
\end{tabular}

* At $\mathrm{pH}=5.8$ in presence of $1.0 \mathrm{M}-\mathrm{MeCO}_{2} \mathrm{Na}$. † Rate for 2-methylindole.

value of $\bar{k}_{2}$ (equivalent to $k_{2}$ under these conditions) is ca. 9-fold larger than that for 2-methylindole. This difference is accommodated (see earlier) by the increased basicity (reactivity) of the 2-methyl-4,6-di-t-butyl compound, ${ }^{25}$ so any steric retardation by the 4 -t-butyl substituent must be quite small. This matter is discussed further below.

The acidity dependence of the coupling rate of $p$-methoxybenzenediazonium salts was studied in a manner analogous to that for 2-methylindole. Thus in dilute aqueous $\mathrm{H}_{2} \mathrm{SO}_{4}$ containing only $4 \%(\mathrm{v} / \mathrm{v})$ dioxan, the data are well fitted to equation (7) as shown by the reasonable linearity of Figure 3.

${ }^{23}$ B. C. Challis and R. Iqbal, unpublished results.

24 E. M. Millar, Ph.D. Thesis, London, 1968.

25 B. C. Challis and H. S. Rzepa, to be published. 
The agreement between $\mathrm{p} K_{\mathrm{A}}$ values obtained from the slope $(+0.6)$ and the intercept $(+0.1)$ of Figure 3 , however, is only modest, probably because protonation of 2-methyl4,6-di-t-butylindole does not follow the usual $h_{\mathrm{I}}$ acidity function. ${ }^{21}$ Nonetheless, these values clearly demonstrate that the di-t-butylated indole is more basic than 2-methylindole $\left(\mathrm{p} K_{\mathrm{A}}-0.30\right.$ in $\left.\mathrm{H}_{2} \mathrm{O}\right){ }^{21}$

The rate of coupling at higher $\mathrm{pH}$ was examined in dilute tetraborate buffers, but the \% dioxan had to be increased to $40 \%(\mathrm{v} / \mathrm{v})$ for solubility reasons. Evidence summarised by Figure 4 demonstrates that both diazo-deprotonation and -dedeuteriation rates are well fitted by equation (8), so both the neutral indole and the indolyl anion are reactive under these conditions. Evaluation of the data leads to parameters (9) and (10), but neither one is directly comparable to those for 2-methylindole because of the change

$$
\begin{aligned}
& \tilde{k}_{2}{ }^{\mathrm{H}}=3.1+5.9 \times 10^{-10} /\left[\mathrm{H}_{3} \mathrm{O}^{+-}\right] \\
& \bar{k}_{2}{ }^{\mathrm{D}}=1.5+3.6 \times 10^{-10} /\left[\mathrm{H}_{3} \mathrm{O}^{+}\right]
\end{aligned}
$$

in solvent. However, since the operational $\mathrm{pH}$ values (i.e. as measured with the glass electrode) for $20 \%(\mathrm{v} / \mathrm{v})$ and $\mathbf{4 0} \%(\mathrm{v} / \mathrm{v})$ aqueous dioxan are reasonably equivalent, ${ }^{26}$ only differences in the $K_{\mathrm{E}}$ ionisation constants are significant.

The different slopes and intercepts of the two plots in Figure 4 imply that coupling to both 2-methyl-4,6-di-tbutylindole and its conjugate base is subject to a deuterium isotope effect. After correction for the isotopic purity of the $\left[3-{ }^{2} \mathrm{H}\right]$ isomer $(82 \%)$, the isotopic rate ratio for the neutral molecule reaction $k_{2}{ }^{\mathrm{H}} / k_{2} \mathrm{D}=2.6 \pm 0.3$ : for the

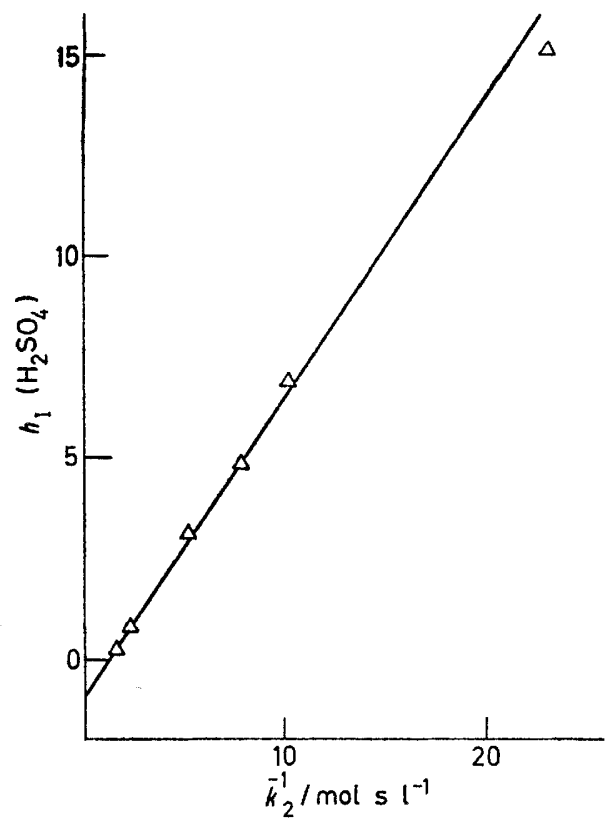

Figure 3 Acidity dependence for the diazodeprotonation of 2 methyl-4,6-di-t-butylindole in $4 \%(\mathrm{v} / \mathrm{v})$ aqueous dioxan- $\mathrm{H}_{2} \mathrm{SO}_{4}$ at $25^{\circ}$

anion reaction, ${k_{2}}{ }^{\mathrm{H}} /{k_{2}}{ }^{\mathrm{D}}=2.0 \pm 0.2$ after correction as above and assuming that $K_{\mathrm{E}}$ is unaffected by isotopic substitution. The corresponding tritium isotope effect was measured for coupling of $p$-methoxybenzenediazonium ion to the neutral indole in phosphate buffers ( $\mathrm{pH} 7.37$ ) at $25^{\circ}$ by following the rate of tritium loss and azo-product formation simultaneously (see Experimental section): these data gave $k_{2}{ }^{\mathrm{H}} / k_{2}{ }^{\mathrm{T}}=\mathbf{5 . 1} \pm 0.3$.

The observation of significant hydrogen isotope effects implies that base catalysis by the buffer components might

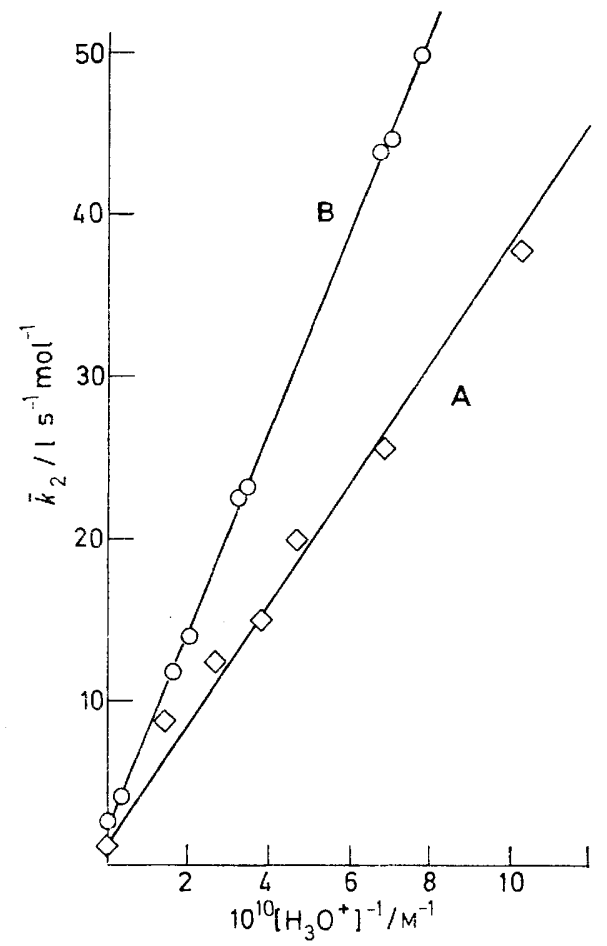

FIgure 4 Acidity dependence for the diazocoupling of $\mathbf{A}$ [3-2 $\left.\mathrm{H}_{1}\right]-$ and $B,\left[3-{ }^{1} \mathrm{H}_{1}\right]-2$-methyl-4,6-di-t-butylindole with, $p$-methoxybenzenediazonium ion in $40 \%(\mathrm{v} / \mathrm{v})$ aqueous dioxan tetraborate buffers at $25^{\circ}$

be expected for coupling to 2-methyl-4,6-di-t-butylindole. Addition of $1.0 \mathrm{M}-\mathrm{MeCO}_{2} \mathrm{Na}$ to the reaction mixture produced an insignificant increase in the reaction rate (see Table 9), so it seems that solvent water competes successfully with the buffer components in removing the proton from the Wheland intermediate.

\section{DISCUSSION}

All the experimental findings are consistent with a classical $A-S_{\mathrm{E}} 2$ mechanism (Scheme 3) for the diazocoupling reaction. Either the neutral indole or the indolyl anion is involved depending on the experimental conditions and application of steady state theory to each pathway gives equations (11) and (12) as familiar

$$
\begin{aligned}
& k_{2}=k_{\mathrm{a}} /\left(\mathbf{1}+k_{-\mathrm{a}} / k_{\mathrm{b}}[\mathrm{B}]\right) \\
& k_{\mathrm{2}}{ }^{\prime}=k_{\mathrm{a}}{ }^{\prime} /\left(\mathbf{1}+k_{-\mathrm{a}}{ }^{\prime} / k_{\mathrm{b}}{ }^{\prime}[\mathrm{B}]\right)
\end{aligned}
$$

expressions relating the observed molecular rate coefficients to the invididual steps in Scheme 3. Reaction rates increase with the basicity (reactivity) of the substrate and are much faster for the indolyl anion: the rate ratio for coupling of $p$-methoxybenzenediazonium

${ }_{26}$ L. G. Van Uitert and C. G. Haas, J. Amer. Chem. Soc., 1953, 75, 451 . 
ion to 2-methylindolyl anion relative to the neutral substrate is $k_{2}{ }^{\prime} / k_{2} c a .2 \times 10^{8}$. This compares satisfactorily with equivalent ratios for diazo-coupling to 2-naphthol ${ }^{27}$ and to pyrrole ${ }^{9}$ (both $c a .10^{8}$ ) and for hydrogen exchange at the 3 -position of indoles ( $\mathrm{ca}$. $\left.10^{7}\right) .{ }^{28}$ Further, the magnitude of $k_{2}$ for reaction of the 2 -methylindolyl anion with $p$-methoxybenzenediazonium competitive $N$ - and $C$-coupling should be much smaller, because the 3 -position is inherently more basic than the para-position of $N$-methylaniline. $N$-Coupling is probably therefore insignificant and careful examination of the reaction products by both t.l.c. and u.v. gave no evidence of triazene formation. Further, slow $N$ coupling followed by a rapid thermal $[1,3]$ sigmatropic

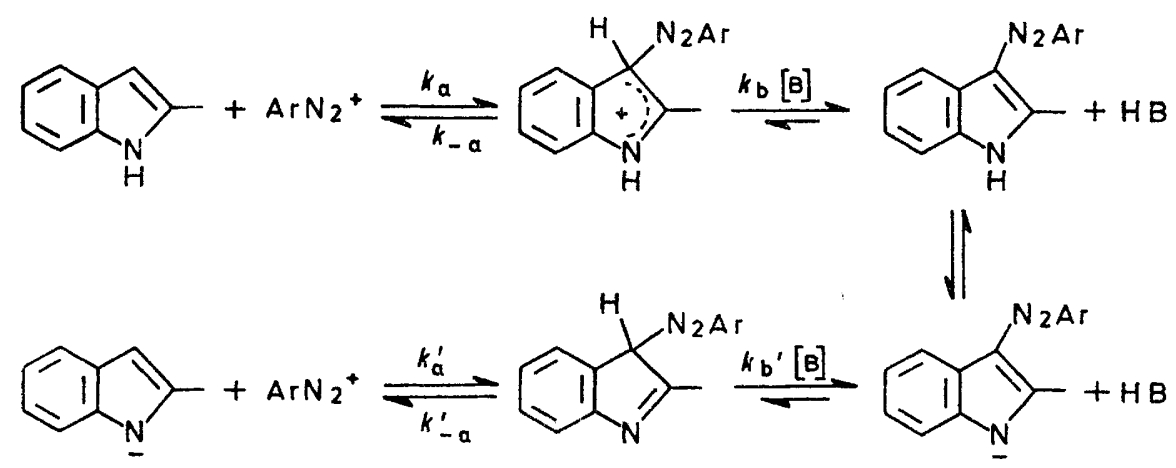

Scheme $3 A-S_{\mathbf{E}} 2$ Mechanism for diazo-coupling to neutral indole and the indolyl anion

salts is only ca. 100 fold less than that expected for a diffusion controlled reaction. Also reaction rates increase with increasing reactivity of the electrophilic diazonium ion and the value of $\rho \mathbf{3 . 3}$ for the Hammett $\left(\rho \sigma^{+}\right)$plot compares favourably with $\rho 4.0$ and $4.3-4.6$ for diazo-coupling to aromatic amines ${ }^{29}$ and pyrroles, ${ }^{9}$ respectively. The activation parameters, particularly the highly negative $\Delta S^{\ddagger}$, are typical of other $A-S_{E} 2$ reactions. ${ }^{30}$

Because of the potential 1,3-ambident nucleophilic properties of the indole nucleus, there is a possibility, not eliminated by any of the findings discussed above, that 3-coupling proceeds by way of a triazene intermediate (I) or its conjugate acid. This question is of crucial importance, of course, to an interpretation of<smiles>Cc1cc2ccccc2n1/N=[W]\Br</smiles>

3-H isotope effects, particularly if formation of the triazene proceeds at a comparable rate to that of the 3-azo-product. Triazene formation is well known ${ }^{\mathbf{3 1}}$ for primary and secondary aromatic amines and a reasonably comparable case to indoles is that of $N$-methylaniline, discussed by Beranek and his colleagues. ${ }^{29} a$ Here, $N$ coupling is faster than $C$-coupling by a factor of 25 , but is reversible at low $\mathrm{pH}$ to yield the thermodynamically stabler $C$-coupled aminoazobenzene.

For the neutral indoles, at least, the rate ratio for 270.

${ }^{27}$ K. Valter and V. Sterba, Coll. Czech. Chem. Comm., 1972, 37,

${ }_{28}$ H. S. Rzepa, Ph.D. Thesis, London, 1974.

29 (a) V. Beranek, H. Korinkova, P. Vetesnika, and M. Vecera Coll. Czech. Chem. Comm., 1972, 37, 282; (b) V. Beranek and M. Vecera, ibid., 1969, 34, 2753. rearrangement can be ruled out by the antarafacial pathway required from orbital symmetry considerations, ${ }^{32}$ and a dissociative mechanism, comprising rapid $N$-coupling followed by slower $C$-coupling is equivalent (as far as isotope effects are concerned) to direct $C$ coupling and is unlikely because of the exact congruence between u.v. coupling and detritiation rates for $\left[3{ }^{3} \mathrm{H}_{1}\right]-2-$ methylindole. Also, the deuterium isotope effect for coupling to 2-methyl-4,6-di-t-butylindole confirms unequivocally that $N$-coupling is unimportant in this case: although the tritium isotope effect $\left(k_{2}{ }^{\mathrm{H}} / k_{2}{ }^{\mathrm{T}} 5.1\right)$ could be explained by fast $N$-coupling followed by $c a$. five-fold slower rearrangement to the 3-azo-product, the deuterium isotope effect $\left(k_{2} \mathrm{H} / k_{2}{ }^{\mathrm{D}} 2.6\right)$ cannot, because it is evaluated from equivalent experimental measurements and there is no possibility of a secondary 3-deuterium isotope effect of this magnitude on coupling to nitrogen.

The position is less clear cut with respect to $N$ coupling of the indolyl anions, but, significantly, no evidence of triazene formation was again found from careful u.v. and t.l.c. examination of the reaction products.

Evidently, with the exception of 2 -methyl-4,6-di-tbutylindole, electrophilic attack by the diazonium ion (steps $k_{\mathrm{a}}$ and $k_{\mathrm{a}}{ }^{\prime}$ of Scheme 3 ) at the 3 -position is normally rate limiting for azo-coupling to both neutral indoles and the indolyl anions in aqueous solvents. By implication, it seems that $\mathrm{H}_{2} \mathrm{O}$ is a sufficiently effective base to ensure that both $k_{-\mathrm{b}} / k_{\mathrm{a}}[\mathrm{B}]<1$ and $k_{-\mathrm{b}}{ }^{\prime} / k_{\mathrm{a}}{ }^{\prime}[\mathrm{B}]<1$ so that equations (11) and (12) reduce to $k_{2}=k_{\mathrm{a}}$ and $k_{2}{ }^{\prime}=k_{\mathrm{a}}{ }^{\prime}$, respectively. It follows that a change in the

30 M. A. Matesich, J. Org. Chem., 1967, 32, 1258.

${ }^{31}$ I. T. Millar and H. D. Springall in N. V. Sidgewick, 'The Organic Chemistry of Nitrogen,' Clarendon Press, Oxford, 1966, 3rd edn., p. 602.

32 R. B. Woodward and R. Hoffmann, Angew. Chem. Internat. Edn., 1969, 8, 781 . 
rate-limiting step might be effected by coupling in aprotic solvents where the water concentration is significantly lower and reaction under these conditions was examined briefly. For 4-methyl-2-t-butylindole, small deuterium isotope effects (ca. 2) were found for coupling to toluene- $p$-diazonium salts in both nitrobenzene and nitromethane.

Findings for 2-methyl-4,6-di-t-butylindole show that a change of rate-limiting step, from attack of the electrophile to expulsion of the proton (step $k_{\mathrm{b}}$ of Scheme 3) is also effected by severe steric hindrance at the reactive site. Examination of the experimental isotopic rate ratios, however, clearly demonstrates that this change is incomplete with $k_{-\mathrm{b}} \simeq k_{\mathrm{a}}[\mathrm{B}]$. In particular, the Swain-Schaad ${ }^{33}$ exponent $(r)$ relating the tritium and deuterium isotope effects [equation (13)],

$$
r=\log \left(k_{\mathbf{2}}{ }^{\mathrm{H}} / k_{\mathbf{2}}{ }^{\mathrm{T}}\right) / \log \left(k_{\mathbf{2}}{ }^{\mathrm{H}} / k_{\mathbf{2}}{ }^{\mathrm{D}}\right)=1.71
$$

falls well outside the normally expected limits of $1.33<r<1.55 .^{34}$ This is a direct consequence of $k_{2} \mathrm{~L} *$ being a composite rate coefficient as defined by equation (14). By assuming that the deuterium and

$$
k_{\mathbf{2}}{ }^{\mathrm{L}}=k_{\mathrm{a}} /\left(1+k_{-\mathrm{a}} / k_{\mathrm{b}} \mathrm{L}[\mathrm{B}]\right)
$$

tritium isotope effects for the $k_{\mathrm{b}}$ step fully comply with the Swain-Schaad relationship ${ }^{33}$ (i.e. $\log k_{\mathrm{b}}^{\mathrm{H}} / k_{\mathrm{b}}^{\mathrm{T}}=$ $1.442 \log k_{\mathrm{b}}{ }^{\mathrm{H}} / k_{\mathrm{b}} \mathrm{D}$ ) (calculations show that secondary isotope effects on $k_{\mathrm{a}}$ and $k_{-\mathrm{a}}$ are negligible), the observed isotopic rate coefficients $\left(k_{2} \mathrm{~L}\right)$ can be determined via equation (12) to give $k_{\mathrm{b}}{ }^{\mathrm{H}} / k_{\mathrm{b}} \mathrm{D}=7 ; k_{\mathrm{b}}{ }^{\mathrm{H}} / k_{\mathrm{b}}{ }^{\mathrm{T}}=18$; and $k_{-a} / k_{\mathrm{b}}{ }^{\mathrm{H}}[\mathrm{B}] \quad c a .0 .31$. These isotopic rate ratios are ' normal' in magnitude and very similar to those reported by Zollinger ${ }^{1}$ for coupling to hydroxynaphthalenesulphonic acids. It should be emphasized however, that their accuracy is low because of the quality of the experimental data $( \pm 5 \%)$ and the approximation made, but they show how misleading isotopic rate ratios can be if proton transfer is not fully rate-limiting.

Our findings for sterically hindered indoles parallel those reported by Zollinger and his colleagues ${ }^{1,7}$ for diazo-coupling to naphthols. They have firmly established in several investigations that substantial deuterium isotope effects, and base catalysis, are associated with sterically hindered substrates. From examination of the effects of peri-substituents on the 1-coupling rates of 2 -naphthols, Snychers and Zollinger ${ }^{7}$ have argued that the rate of electrophilic attack ( $\operatorname{step} k_{\mathrm{a}}$ of Scheme 1) is not subject to steric hindrance so the observation of a deuterium isotope effect, associated with an increase in the $k_{-\mathrm{a}} / k_{\mathrm{b}}[\mathrm{B}]$ ratio, must stem from a decrease in $k_{\mathrm{b}}$ rather than an increase in $k_{-a}$ i.e. only expulsion of the proton is subject to steric interactions. The same argument applies satisfactorily for coupling to indoles. If $k_{-\mathrm{a}} / k_{\mathrm{b}}[\mathrm{B}] \mathrm{ca} .0 .31$ (see below) for reaction of $p$-methoxy-

* The symbol L refers to isotopic hydrogen, i.e. $\mathrm{H}, \mathrm{D}$, or $\mathrm{T}$.

${ }^{33}$ C. G. Swain, E. S. Stivers, J. F. Reuwar, and L. J. Schaad, $J$. Amer. Chem. Soc., 1958, 80, 5855. benzenediazonium salts with neutral 2-methyl-4,6-di-tbutylindole, then $k_{\mathrm{a}}$ is $c a .12$ fold larger than for the comparable reaction of 2 -methylindole. This is consistent with their different basicities (reactivities), which implies that the $k_{\mathrm{a}}$ step is not subject to steric hindrance from the 4-t-butyl substituent. For coupling to the indolyl anions, the $k_{2}{ }^{\prime} K_{\mathrm{E}}$ product is closely similar for both the 2-methylindolyl and 2-methyl-4,6-di-t-butylindolyl reactants. Since the difference in $K_{\mathrm{E}}$ for each compound is probably $<4,{ }^{28}$ the retardation induced by the 4-t-butyl substituent on $k_{\mathrm{a}}{ }^{\prime}$ is less than a factor of 5 .

Following Snychers and Zollinger, ${ }^{7}$ the deduction that steric hindrance operates only on proton expulsion from the Wheland intermediate, and not on attack by the electrophilic reagent, is indicative of an asymmetric $\sigma$-complex for the Wheland intermediate, and a correspondingly 'reactant-like' transition state (II) even

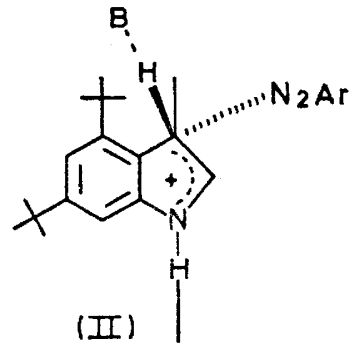

for the proton-expulsion step. The incoming diazonium ion occupies a pseudo-axial position (towards the perpendicular to the indole ring) and is not greatly influenced by the periplanar t-butyl substituent: the leaving proton lies closer to the plane of the indole ring, and, because of the preferred linear reaction co-ordinate for proton transfer, the incoming base is subject to steric hindrance. Consequently, the rate of proton transfer is substantially decreased.

The introduction of further steric constraints into the substrate eventually affects the rate of diazonium ion attack. Thus coupling to $2,4,6$-tri-t-butylindole is at least $10^{3}$-fold less than expected from its basicity, and the eventual products largely consist of dealkylated azoindoles. It therefore seems that hindering the indole sufficiently to make proton expulsion completely rate limiting introduces undesirable side reactions.

Although diazo-coupling to indoles seems an unsuitable reaction for examining the kinetics of proton transfer, our results demonstrate that steric effects can be useful in determining the conformational properties of the transition state for proton transfer in these and related reactions.

We thank the Salters' Company for a Scholarship to H. S. R. and the S.R.C. for an equipment grant.

[4/2236 Received, 29th October, 1974] 34 M. J. Stern and P. C. Vogel, J. Amer. Chem. Soc., 1971, 93,
4664. 